\title{
Early Life History of Rhodeus Fish (R. uyekii and R. ocellatus) in the Nakdong River Water System
}

\author{
Jae-Min Park ${ }^{1}$ and ${ }^{\dagger}$ Kyeong-Ho Han ${ }^{2}$ \\ ${ }^{1}$ Gyeongsangbuk-Do Native Fish Business Center, Uiseong 37366, Korea \\ ${ }^{2}$ Marine Technology Undergraduate, Chonnam National University, Yeosu 59626, Korea
}

\begin{abstract}
The purpose of this study is to investigate the early life history of the Rhodeus fish, Rhodeus uyekii and R. ocellatus, in the Nakdong River to use as the preliminary data for the systematic study. The embryos used in the study were fertilized eggs (embryo) and larvae after artificial fertilization. The long diameter of the eggs of the R. uyekii was 3.39-3.97 mm (average 3.68 $\pm 0.41 \mathrm{~mm}, \mathrm{n}=30$ ) and the short diameter was $1.36-1.55 \mathrm{~mm}$ (average $1.45 \pm 0.13 \mathrm{~mm}, \mathrm{n}=30$ ). The long diameter of the eggs of the $R$. ocellatus was $2.53-2.71 \mathrm{~mm}$ (average $2.62 \pm 0.12 \mathrm{~mm}, \mathrm{n}=30$ ) and the short diameter was $1.47-1.60 \mathrm{~mm}$ (average $1.53 \pm 0.09 \mathrm{~mm}, \mathrm{n}=30$ ). Hatching time was 48 hours for the $R$. uyekii and 50 hours for the $R$. ocellatus given that the average water temperature was $21.5^{\circ} \mathrm{C}$. The hatched larvae were $4.95-5.00 \mathrm{~mm}$ (average $4.98 \pm 0.04 \mathrm{~mm}, \mathrm{n}=5$ ) for the $R$. uyekii and the total length was 3.66-3.69 mm (average 3.67 $\pm 0.02 \mathrm{~mm}, \mathrm{n}=5$ ) for the $R$. ocellatus. $R$. uyekii was found to be 15.5-15.8 $\mathrm{mm}$ at total length (average $15.6 \pm 0.21 \mathrm{~mm}, \mathrm{n}=5$ ) on the 56 days after hatching with the number of dorsal fins being iii-9, anal fins iii-10, ventral fins iii-5. The $R$. ocellatus was found to be 15.8-16.0 mm (average $15.9 \pm 0.14 \mathrm{~mm}, \mathrm{n}=5$ ) at total length on the 58 days with the number of dorsal fins being iii-11, anal fins iii-12 and ventral fins iii- 5 where the number of all fin stalks reached maximum.
\end{abstract}

Key words : Egg development, Juveniles, Larvae, Rhodeus uyekii, Rhodeus ocellatus

\section{INTRODUCTION}

Aceilognathinae fish are small with unusual scattering habits that utilize freshwater marine bivalvia as a host for spawning. There are about 40 species in China, Japan, Taiwan and northern Vietnam, and one species in Europe (Arai, 1988; Bănărescu, 1990). 14 species of 2 genera including $R$. hondae have been extinct and among them Rhodeus uyekii is an indigenous species and has been known as an ornamental fish with beautiful colors together with $R$. ocellatus (Kim et al., 2005; Kim et al., 2012a).
Physical habitats relating to flow velocity, water depth and river bed structure have changed due to recent river and beam construction where even the number of Aceilognathinae fish and the bivalvia used as a spawning host have been reduced making their conservation urgent. At present, R. pseudosericeus, Acheilognathus signifer, A. somjinensis have gradually reduced in numbers and are under protection by the Ministry of Environment designated as wild animals and plants.

Studies on early life history are very important to identify the systematic differences with similar species and to show

\footnotetext{
Manuscript received January 7, 2018, Received in revised form March 18, 2018, Accepted March 24, 2018

$\dagger$ Corresponding Author : Kyeong Ho Han, Marine Technology Undergraduate, Chonnam National University, Yeosu 59626, Korea. Tel: +82-61-6597163, Fax: +82-61-659-7169, E-mail: aqua05@jnu.ac.kr
}

This is an Open Access article distributed under the terms of the Creative Commons Attribution Non-Commercial License (http:// creative-commons.org/licenses/by-nc/3.0) which permits unrestricted non-commercial use, distribution, and reproduction in any medium, provided the original work is properly cited. 
the species' specific traits through morphological and physiological characteristics of the eggs, embryo genesis and early growth process (Blexter, 1974; Balon, 1985; Song \& Choi, 2000). Based on this, it is possible to utilize various techniques such as securing seed production technology for preservation and restoration of fish species. Therefore in this study, we investigated the developmental process and larvae formation the R. uyekii and R. ocellatus, (which belong to the Aceilognathinae Rhodeus) in order to provide preliminary data for systematic studies and species preservation. These species are threatened by environmental changes.

\section{MATERIALS AND METHODS}

\section{Broodstock culture}

The broodstock used in the study were sampled in deep nets $(3 \times 3 \mathrm{~mm})$ from the Nakdong river waterside located in Uiseong Gun, Gyeongbuk Province from May-June 2015, and were transported to the laboratory after oxygen pavement. The broodstock was cultured in a rectangular glass tank $(35 \times 30 \times 35 \mathrm{~cm})$ and were fed through circulation filtration using a sponge filter. The water temperature was maintained at $20.5-22.5^{\circ} \mathrm{C}$ (average $21.5 \pm 1.0^{\circ} \mathrm{C}$ ). Assorted feeds were given twice a day. In order to induce spawning, 4 Unio douglasiaes were placed in a square container filled with sand inside the tank.

\section{Development of eggs and larvae}

To observe the developmental process of the eggs, mature broodstock were selected and modified using the wet method. The shape and size of the embryos were measured using stereoscopic microscopes (Nikon SMZ18, Japan). The embryos were housed in a glass Petri dish $(\varnothing 10 \mathrm{~cm})$ and the temperature of the breeding was the same as that of the broodstock culture. $80 \%$ of the breeding water was exchanged once a day until right before hatching. Larvae culture was continuously cultivated in a Petri dish immedi- ately after hatching before swimming started and from the postflexion stage to the juvenile stage in a glass tank $(35 \times 30 \times 35 \mathrm{~cm})$. The water temperature was kept the same as for the embryos, and the breeding water was changed by $50 \%$ every week. Two to three $1 \mathrm{~mL}$ nauplius larvae of Artemia sp. were provided as the feed for the larvae from immediately after hatching to 45 days after. Frozen Blood warm (Hikari China) and $500 \mu \mathrm{m}$ of assorted feed (Dry feed, Jeilfeed Korea) were mixed and supplied after 45 days.

The shape of the larvae was observed from right after hatching to the larvae stage. Also, 1 fish was collected per day from the day of hatching to day 5 and 1 fish per every 5 days were collected starting from the 6 days after hatching using the anesthetic (MS-222, Ethyl 3-aminobenzoate methanesulfonate, Sigma Aldrich Co., St. Louis, USA) for measurement and observation up to $0.01 \mathrm{~mm}$ using a stereomicroscope and a universal projector (Nikon JP V-12B, Japan). The shape development stage of the larvae was classified by Okiyama (1988).

\section{RESULTS}

\section{Shape and size of eggs}

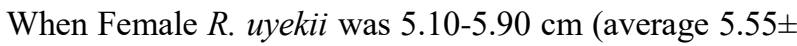
$0.57 \mathrm{~cm}, \mathrm{n}=10$, Fig. 1), the number of eggs laid was 13-22 eggs (average 17 eggs) and the length of the female ovipositor was $3.08-3.59 \mathrm{~cm}$ (average $3.34 \pm 3.61 \mathrm{~cm}$ ). The ratio of the ovipositor length to egg length was $60.4-60.8 \%$ (average 60.6\%). The shape of the egg was pear shaped and the color of the yolk was light yellow and opaque. After fertilization, the longest diameter of the eggs were 3.39$3.97 \mathrm{~mm}$ (average $3.68 \pm 0.41 \mathrm{~mm}, \mathrm{n}=30$ ) and the shortest were 1.36-1.55 mm (average 1.45 $\pm 0.13 \mathrm{~mm}, \mathrm{n}=30$ ).

When the female $R$. ocellatus was $6.46-6.58 \mathrm{~cm}$ (average $6.52 \pm 0.08 \mathrm{~cm}, \mathrm{n}=10$, Fig. 1), the number of eggs laid per female was 18-24 eggs (average 21 eggs) and the length of the ovipositor of the female was $1.82-2.00 \mathrm{~cm}$ (average $1.91 \pm 0.13 \mathrm{~cm}$ ). The ratio of ovipositor length to 


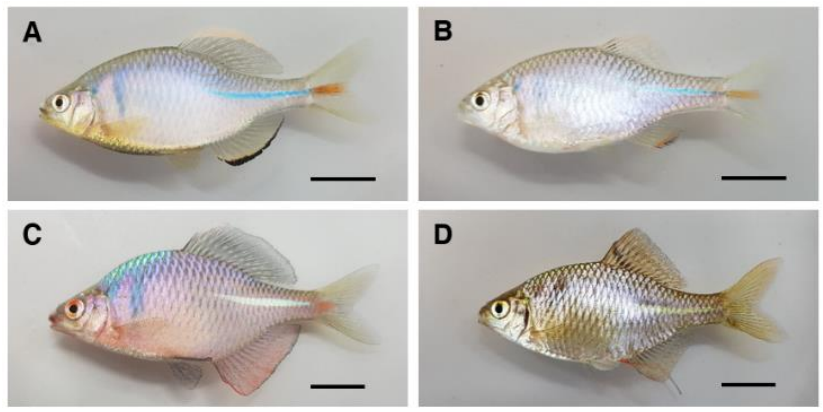

Fig. 1. Morphology of broodstock. A: Rhodeus uyekii (ð), B: R. uyekii (ㅇ), C: R. ocellatus (đ), D: R. ocellatus (우).

total length was 28.2-30.4\% (average 29.3\%). The shape of the egg was pear shaped. There was no oil globule and the yolk color was the same as the $R$. uyekii egg. The longest egg diameter after filtering was 2.53-2.71 mm (average $2.62 \pm 0.12 \mathrm{~mm}, \mathrm{n}=30$ ) and the short was $1.47-1.60 \mathrm{~mm}$ (average $1.53 \pm 0.09 \mathrm{~mm}, \mathrm{n}=30$ ).

\section{Egg formation process \\ 1) Rhodeus uyekii}

Egg formation process was observed in 15 stages (A-O) as shown in Fig. 2. Each hatching time is shown in Table 1. The egg right after fertilization started to absorb moisture right away and the yolk and membrane had not separated yet (Fig. 2A).

At 30 minutes after fertilization, the micropyle part and yolk began to separate and a gap was formed between the yolk and the membrane. At 1 hour and 30 minutes after fertilization, protoplasm was separated from the upper part of the yolk from the micropyle, and the germinal spot occupying $1 / 5$ of the yolk (Fig. $2 \mathrm{~B}$ ).

At 2 hours after fertilization, the central upper part of the germinal spot was divided into two galectins and spread downward forming two blastomeres were bisected

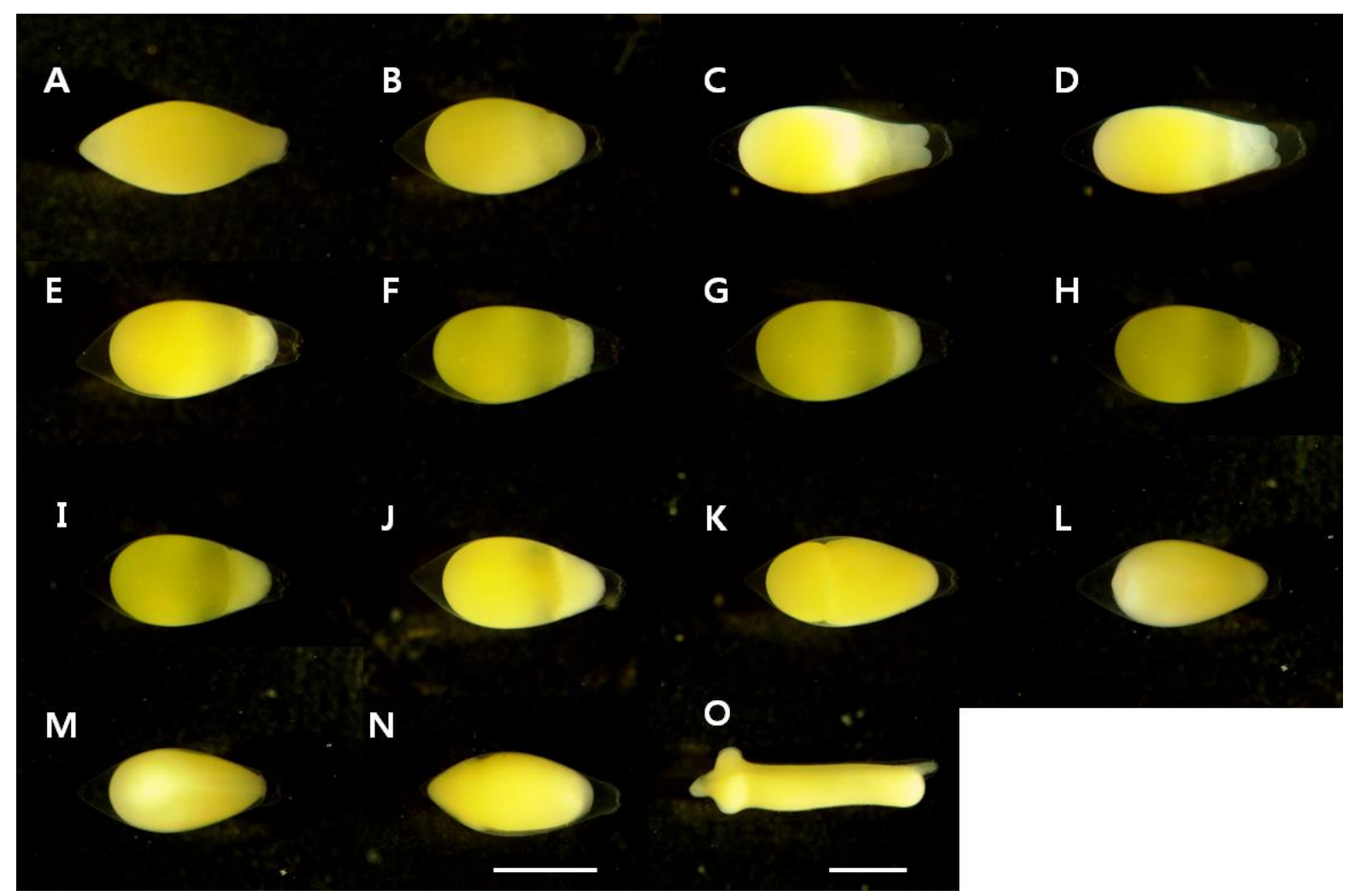

Fig. 2. Egg development of the Rhodeus uyekii. Scale bars=1.0 mm. Time required for each development stage is shown in Table 1. 
Table 1. Eggs and embryonic development of Rhodeus uyekii at water temperature $21.5 \pm 1.0{ }^{\circ} \mathrm{C}$

\begin{tabular}{|c|c|c|c|}
\hline Stage & Elapsed time & Characters & Fig. 2 \\
\hline \multicolumn{4}{|l|}{ Zygote period } \\
\hline Fertilization & $0 \mathrm{hr} 00 \mathrm{~min}$ & The egg absorbs water & A \\
\hline \multicolumn{4}{|l|}{ Cell cleave period } \\
\hline Blastodisc & $1 \mathrm{hr} 30 \mathrm{~min}$ & Blastodisc is formed & B \\
\hline Two celled egg & $2 \mathrm{hr} 00 \mathrm{~min}$ & 2-1 array of blastomeres & $\mathrm{C}$ \\
\hline Four celled egg & $2 \mathrm{hr} 30 \mathrm{~min}$ & $2-2$ array of blastomeres & $\mathrm{D}$ \\
\hline Eight celled egg & $3 \mathrm{hr} 00 \mathrm{~min}$ & 2-4 array of blastomeres & $\mathrm{E}$ \\
\hline Sixteen celled egg & $4 \mathrm{hr} 30 \mathrm{~min}$ & 4-4 array of blastomeres & $\mathrm{F}$ \\
\hline Thirty-two celled egg & $5 \mathrm{hr} 30 \mathrm{~min}$ & $4-8$ array of blastomeres & G \\
\hline Sixty-four celled egg & $6 \mathrm{hr} 30 \mathrm{~min}$ & $8-8$ array of blastomeres & $\mathrm{H}$ \\
\hline \multicolumn{4}{|l|}{ Blastula period } \\
\hline Morula & $11 \mathrm{hr} 30 \mathrm{~min}$ & The size of the blastomere is getting smaller & I \\
\hline Blastula & $18 \mathrm{hr} 30 \mathrm{~min}$ & The surface of the blastomere coincides with the egg yolk & $\mathrm{J}$ \\
\hline \multicolumn{4}{|l|}{ Gastrula period } \\
\hline Gastrulation $2 / 3$ & $23 \mathrm{hr} 00 \mathrm{~min}$ & Covered $2 / 3$ of egg yolk & K \\
\hline Gastrulation $3 / 3$ & $29 \mathrm{hr} 00 \mathrm{~min}$ & Covered $3 / 3$ of egg yolk & $\mathrm{L}$ \\
\hline Embryonic period & $39 \mathrm{hr} 00 \mathrm{~min}$ & Development of embryo & M \\
\hline Embryo just before hatching & $42 \mathrm{hr} 00 \mathrm{~min}$ & Development of scale-like tubercles & $\mathrm{N}$ \\
\hline Hatching period & $48 \mathrm{hr} 00 \mathrm{~min}$ & There was no movement in the hatched larvae. & $\mathrm{O}$ \\
\hline
\end{tabular}

vertically, reaching the 2-cell stage (Fig. 2C).

At 2 hours and 30 minutes after fertilization, the cells were divided into 4 cells of the same size as where horizontal cleavage occurred reaching the 4-cell stage (Fig. 2D). At 3 hours after fertilization, the cells were divided into 8 cells, reaching the 8-cell stage (Fig. 2E), and 16-cell stage was reached at 4 hours and 30 minutes after fertilization (Fig. 2F). At 5 hours and 30 minutes after fertilization, it reached 32-cell stage (Fig. 2G). At 6 hours and 30 minutes after fertilization, the number of cell divisions increased reaching to 64-cell stage (Fig. $2 \mathrm{H}$ ), and at 11 hours and 30 minutes after fertilization it reached the morula stage where it was hard to count the number of cells (Fig. 2I).

At 18 hours and 30 minutes after fertilization, the surface of the blastomere reached the blastula as it approached the curve (Fig. 2J). At 20 hours after fertilization, germ rings were formed as the edges of the germinal spots thickened, and the germ rings covered the yolk from the upper side and reached the initial gastrula stage.

At 23 hours after fertilization, the germ ring covered about two-thirds of the yolk and reached the mid-gastrula 
stage (Fig. 2K), and the germ ring completely covered the plant pole 29 hours after fertilization (Fig. 2L). At 39 hours after fertilization, polyploids were formed increasing the primordium of the vertebra and the tail developed (Fig. 2M).

At 42 hours after fertilization, the epidermal process started on both sides of the yolk (Fig. 2N). At 47 hours after fertilization, hatching started as the head of the polyploid broke through the opposite side of the micropyle. At 48 hours after fertilization, more than $50 \%$ of the total fertilized eggs (embryo) hatched (Fig. 2O).

At 50 hours after fertilization hatching was complete. Larvae had no movement and there was a pair of pterygoids in front of the yolk and on the abdomen.

\section{2) Rhodeus ocellatus}

Egg formation was observed in 15 stages (A-O) as shown in Fig. 3. The hatching time is shown in Table 2. Right after fertilization the egg started to absorb moisture and a crack had formed between the yolk and the membrane. Separation has not yet occurred (Fig. 2B). At 35 minutes after fertilization, protoplasm was separated from the upper part of the yolk from the micropyle, and there was a germinal spot occupying $1 / 5$ of the yolk (Fig. 2B).

At 1 hour after fertilization, the central upper part of the germinal spot was divided vertically into two blastomeres reaching the 2-cell stage (Fig. 2C). At 2 hours after fertilization, the cells were divided into 4 cells of the same size as each blastomere divided reaching the 4-cell stage (Fig. 3D).

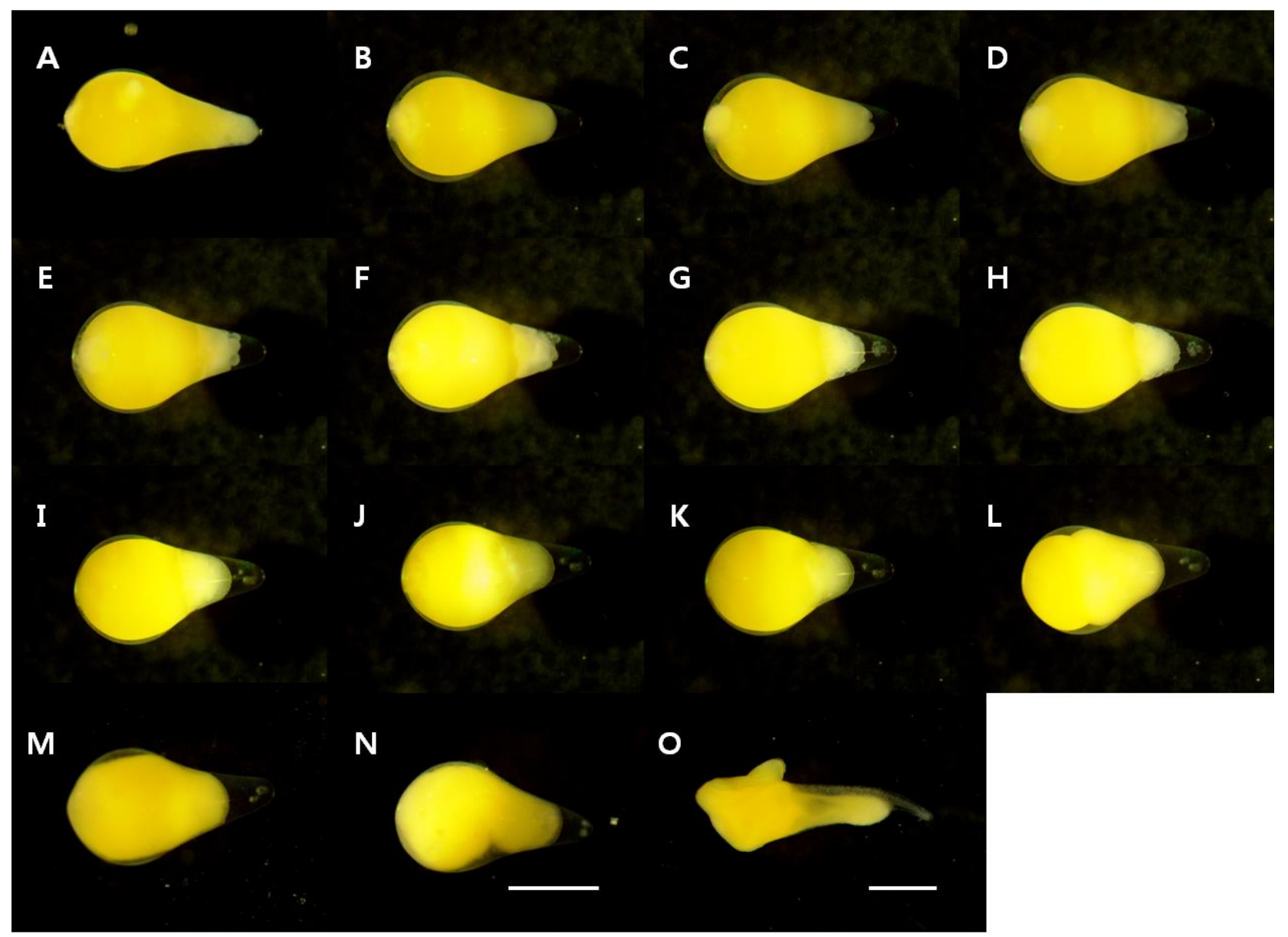

Fig. 3. Egg development of Rhodeus ocellatus. Scale bars=1.0 $\mathrm{mm}$. Time required for each development stage is shown in Table 2. 
Table 2. Eggs and embryonic development of $R$. ocellatus at water temperature $21.5 \pm 1.0^{\circ} \mathrm{C}$

\begin{tabular}{|c|c|c|c|}
\hline Stage & Elapsed time & Characters & Fig. 3 \\
\hline \multicolumn{4}{|l|}{ Zygote period } \\
\hline Fertilization & $0 \mathrm{hr} 00 \mathrm{~min}$ & The egg absorbs water & A \\
\hline \multicolumn{4}{|l|}{ Cell cleave period } \\
\hline Blastodisc & $0 \mathrm{hr} 35 \mathrm{~min}$ & Blastodisc is formed & B \\
\hline Two celled egg & $1 \mathrm{hr} 00 \mathrm{~min}$ & $2-1$ array of blastomeres & $\mathrm{C}$ \\
\hline Four celled egg & $2 \mathrm{hr} 00 \mathrm{~min}$ & 2-2 array of blastomeres & $\mathrm{D}$ \\
\hline Eight celled egg & $2 \mathrm{hr} 30 \mathrm{~min}$ & 2-4 array of blastomeres & E \\
\hline Sixteen celled egg & $4 \mathrm{hr} 30 \mathrm{~min}$ & 4-4 array of blastomeres & $\mathrm{F}$ \\
\hline Thirty-two celled egg & $6 \mathrm{hr} 30 \mathrm{~min}$ & 4-8 array of blastomeres & G \\
\hline Sixty-four celled egg & $9 \mathrm{hr} 30 \mathrm{~min}$ & $8-8$ array of blastomeres & $\mathrm{H}$ \\
\hline \multicolumn{4}{|l|}{ Blastula period } \\
\hline Morula & $11 \mathrm{hr} 30 \mathrm{~min}$ & The size of the blastomere is getting smaller & I \\
\hline Blastula & $13 \mathrm{hr} 00 \mathrm{~min}$ & The surface of the blastomere coincides with the egg yolk & $\mathrm{J}$ \\
\hline \multicolumn{4}{|l|}{ Gastrula period } \\
\hline Gastrulation $1 / 3$ & $17 \mathrm{hr} 30 \mathrm{~min}$ & Covered $1 / 3$ of egg yolk & K \\
\hline Gastrulation $2 / 3$ & $23 \mathrm{hr} 30 \mathrm{~min}$ & Covered $2 / 3$ of egg yolk & $\mathrm{L}$ \\
\hline Embryonic period & $26 \mathrm{hr} 00 \mathrm{~min}$ & Development of embryo & M \\
\hline Embryo just before hatching & $40 \mathrm{hr} 00 \mathrm{~min}$ & The tail is getting longer & $\mathrm{N}$ \\
\hline Hatching period & $50 \mathrm{hr} 00 \mathrm{~min}$ & There was no movement of the hatched larvae. & $\mathrm{O}$ \\
\hline
\end{tabular}

At 2 hours and 30 minutes after fertilization, the blastomere was divided and reached 8-cell stage (Fig. 3E). At 4 hours and 30 minutes after fertilization it reached 16-cell stage (Fig. 3F), at 6 hours and 30 minutes after fertilization it reached 32-cell stage (Fig. 3G) and at 9 hours and 30 minutes after fertilization cell division continued reaching 64-cell stage (Fig. 3H).

At 11 hours and 30 minutes after fertilization it reached the morula stage where it was hard to count the number of cells (Fig. 3I) and at 11 hours and 30 minutes after fertilization, the surface of the blastomere reached the blastula as it approached the curve (Fig. 3J). At 17 hours and 30 minutes after fertilization, germ rings were formed covering $1 / 3$ of the yolk from the upper side and reached the initial gastrula stage (Fig. 3K).

At 23 hours and 30 minutes after fertilization germ rings covered $2 / 3$ of the yolk reaching to the mid gastrula (Fig. $3 \mathrm{~L})$ and 26 hours after fertilization, germ rings completely covered the plant pole forming polyploids, developing the primordium of the vertebra and the tail (Fig. 3M).

At 40 hours after fertilization the base went up to the upper side of the yolk (Fig. $3 \mathrm{~N}$ ) and at 48 hours and 30 
minutes after fertilization, hatching started as the head of the polyploid broke through the opposite side of the micropyle. At 50 hours after fertilization, more than $50 \%$ of the total fertilized eggs (embryo) hatched (Fit. 2O). At 52 hours after fertilization hatching was complete and the larvae had no movement observed.

\section{Larvae form development}

\section{1) Rhodeus uyekii}

Shortly after hatching, the larvae at a total length of 4.95-5.00 $\mathrm{mm}$ (average $4.98 \pm 0.04 \mathrm{~mm}, \mathrm{n}=5$ ) forms a pair of pterygoid processes at the front part of the yolk and the tail protrudes from behind the end of the yolk. The tail was bent at $45^{\circ}$ and there was no polyploid movement. The number of muscle sections was 29-30 (Fig. 4A) at this stage.

On the 1 days after hatching, the preflexion showed a total length of 5.77-5.86 mm $(5.82 \pm 0.06 \mathrm{~mm})$ with appearance of movement from the tail. A pair of protrusions on the front part of the yolk was elongated and one protrusion was formed on the abdomen. The dorsal fin began to form in the tail, optic vesicles started to show and a pair of spiphora began to form (Fig. 4B).

On the 3 days after hatching, the preflexion with a total length of 7.54-7.66 mm (average $7.60 \pm 0.08 \mathrm{~mm}$ ) started to form eyes and the dorsal fin connected from the back to the abdomen were divided according to the anus, and the tail that was bent at $45^{\circ}$ was straight and elongated. The number of muscle segments was 33-34 (Fig. 4C).

On the 5 days after hatching, preflexion grew to be 7.89$8.05 \mathrm{~mm}$ (average $7.97 \pm 0.11 \mathrm{~mm}$ ) and black vesicles were deposited in the eyes, and the length of the protrusions formed on the anterior and posterior sides of yolk became shorter. They started to swim rapidly laterally (Fig. 4D).

On the 11 days after hatching, the mid stage larvae with a total length of $8.51-8.55 \mathrm{~mm}$ (average $8.53 \pm 0.02 \mathrm{~mm}$ ) started opening its mouth and had twig shaped black vesi- cles at the upper part of the head as well as throughout the upper part of the yolk and the middle of the body. The protrusions on the abdomen disappeared, and a pair of protrusions formed on the anterior part of the yolk. Lenses de-

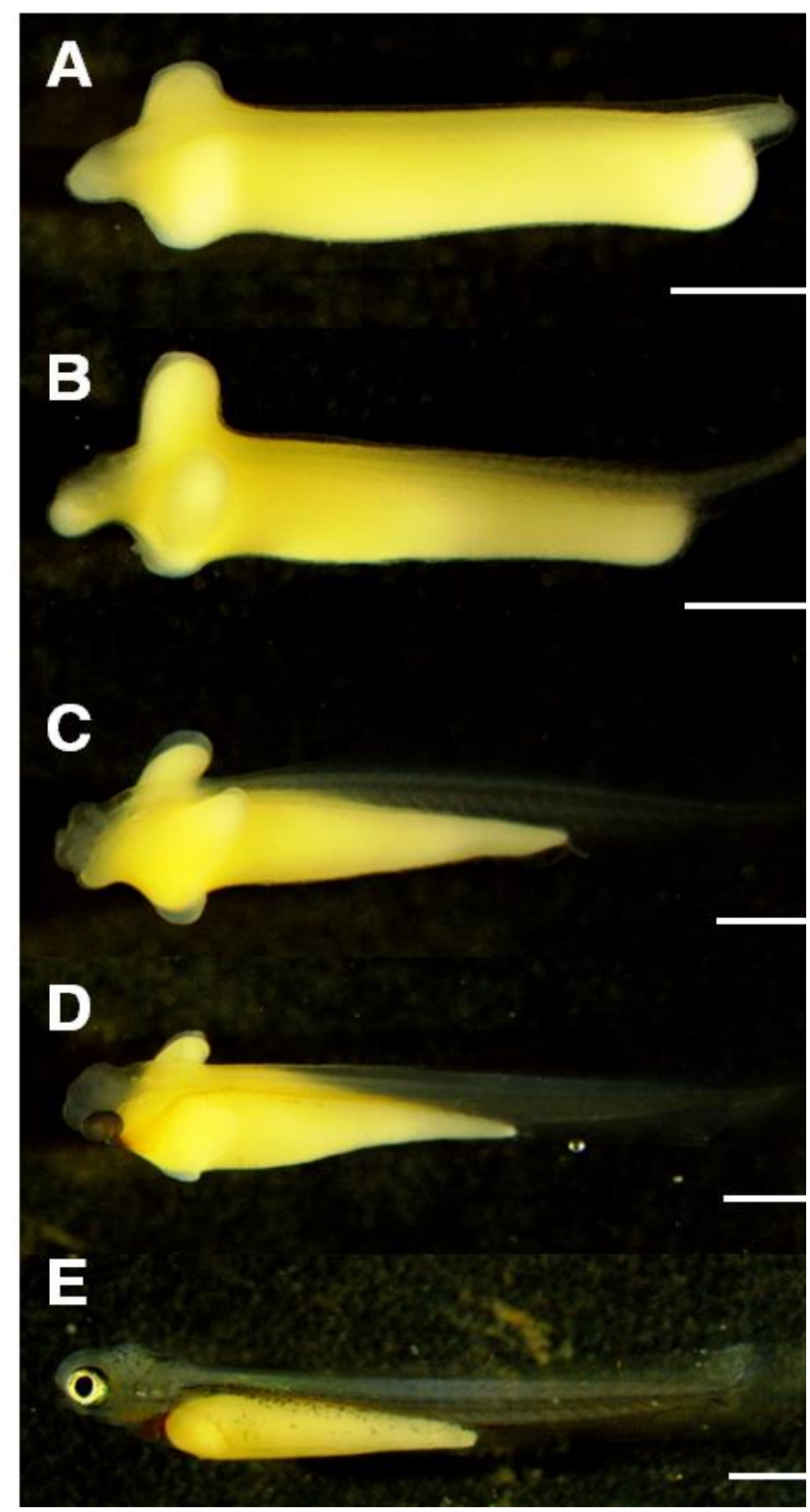

Fig. 4. Preflexion and flexion larvae development of Rhodeus uyekii. A: Newly hatched larvae, 4.98 $\mathrm{mm}$ in total length (TL); B: 1 days after hatching, $5.82 \mathrm{~mm}$ in TL; C: 3 days after hatching, $7.60 \mathrm{~mm}$ in TL; D: 5 days after hatching, $7.97 \mathrm{~mm}$ in TL; E: 11 days after hatching, $8.53 \mathrm{~mm}$ in TL. Scale bars $=1.0 \mathrm{~mm}$. 
veloped in the eyes and a thin elongated rod-shaped scapular bone was formed in the occipital area forming a circular membrane pectoral fin. The tip of the vertebrae began to bend at an angle of $45^{\circ}$, and 18 caudal fin stems were formed (Fig. 4E).

On the 17 days after hatching, the mid stage larvae with a total length of $8.79-8.84 \mathrm{~mm}$ (average $8.81 \pm 0.03 \mathrm{~mm}$ ) started to open their mouths and anus but did not show any feeding behavior and did not completely absorb the yolk. The larvae started floating sideways and the pair of protrusions in front of the yolk was lost. Dorsal fins began to differentiate and nine stalks were formed. The anal fin, which was made of membrane, was separated from the dorsal fin by the reproductive hole, and seven stalks were formed. The number of stems of the caudal fin increased to 20-22 (Fig. 5A).

On the 23 days after hatching, post stage larvae with a total length of 8.91 to $9.03 \mathrm{~mm}$ (average $8.97 \pm 0.08 \mathrm{~mm}$ ) absorbed all the yolk, developed air bladders and floated above water. Black vesicles were deposited on the dorsal and anal fins. The number of stems of each part was 12 for the dorsal fins and 10 for the anal fins and the ventral fin was made of membrane (Fig. 5B).

On the 28 days after hatching, the larvae grew to 10.4$10.6 \mathrm{~mm}$ (average $10.5 \pm 0.14 \mathrm{~mm}$ ) in total length with better swimming ability and increased food intake. The number of the dorsal fins increased to 11 in this period (Fig. 5C).

On the 45 days after hatching, the post stage larvae was 12.4-12.7 mm (average 12.5 $\pm 0.21 \mathrm{~mm}$ ), and black vesicles were darkly colored at the top of the head and scales were formed at the lower abdomen. Three stalks were formed in the ventral fin of the membrane and the number of stems of the anal fins increased to 13 (Fig. 5D).

On the 56 days after hatching juvenile fish that were 15.5-15.7 $\mathrm{mm}$ (average $15.6 \pm 0.21 \mathrm{~mm}$ ) formed scales that started from the abdomen to the middle of the body. The number of fins were III-9 in dorsal fin, iii-10 in anal fin and III-5 in stems of the ventral fin resulting in a complete number of fins (Fig. 5E).

\section{2) Rhodeus ocellatus}

Larvae right after hatching is $3.66-3.69 \mathrm{~mm}$ (average $3.67 \pm 0.02 \mathrm{~mm}$ ) with a pair of pterygoids on each side. There is one protrusion on the abdomen. The tail was directed downwards towards the yolk, the fins were membranous, and no movement was observed (Fig. 6A).

On the 1 days after hatching, the pre-larvae was 4.80-

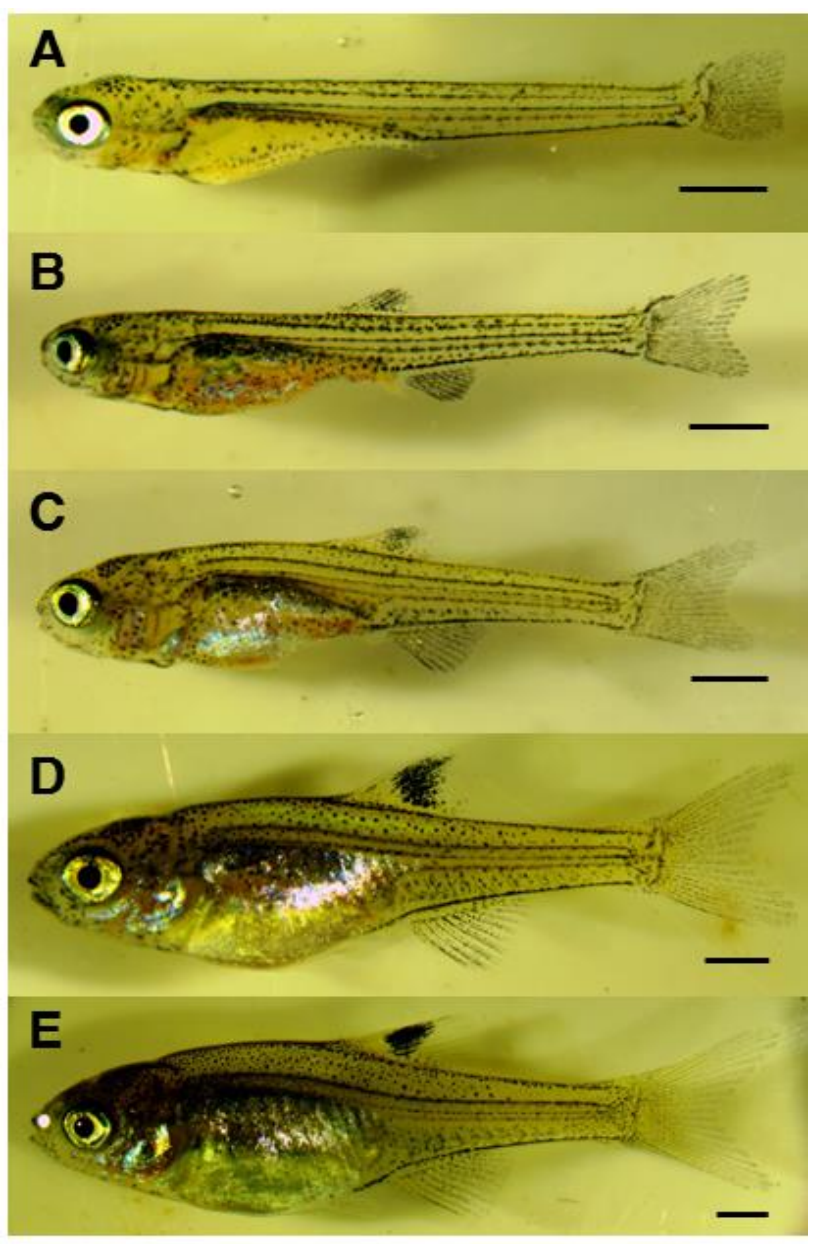

Fig. 5. Flexion and postflexion larvae and juvenile development of Rhodeus uyekii. A: 17 days after hatching, $8.81 \mathrm{~mm}$ in total length (TL); B: 23 days after hatching, $8.97 \mathrm{~mm}$ in TL; C: 28 days after hatching, $10.5 \mathrm{~mm}$ in TL; D: 45 days after hatching, $12.5 \mathrm{~mm}$ in TL; E: 56 days after hatching, $15.6 \mathrm{~mm}$ in TL. Scale bars $=1.0 \mathrm{~mm}$. 
$4.84 \mathrm{~mm}$ (mean $4.82 \pm 0.02 \mathrm{~mm}$ ). The tail elongated and the dorsal fin developed widely. At this time, movement was observed at the tip of the tail and the anus began to develop (Fig. 6B).

On the 3 days after hatching, the pre-larvae were 6.02-

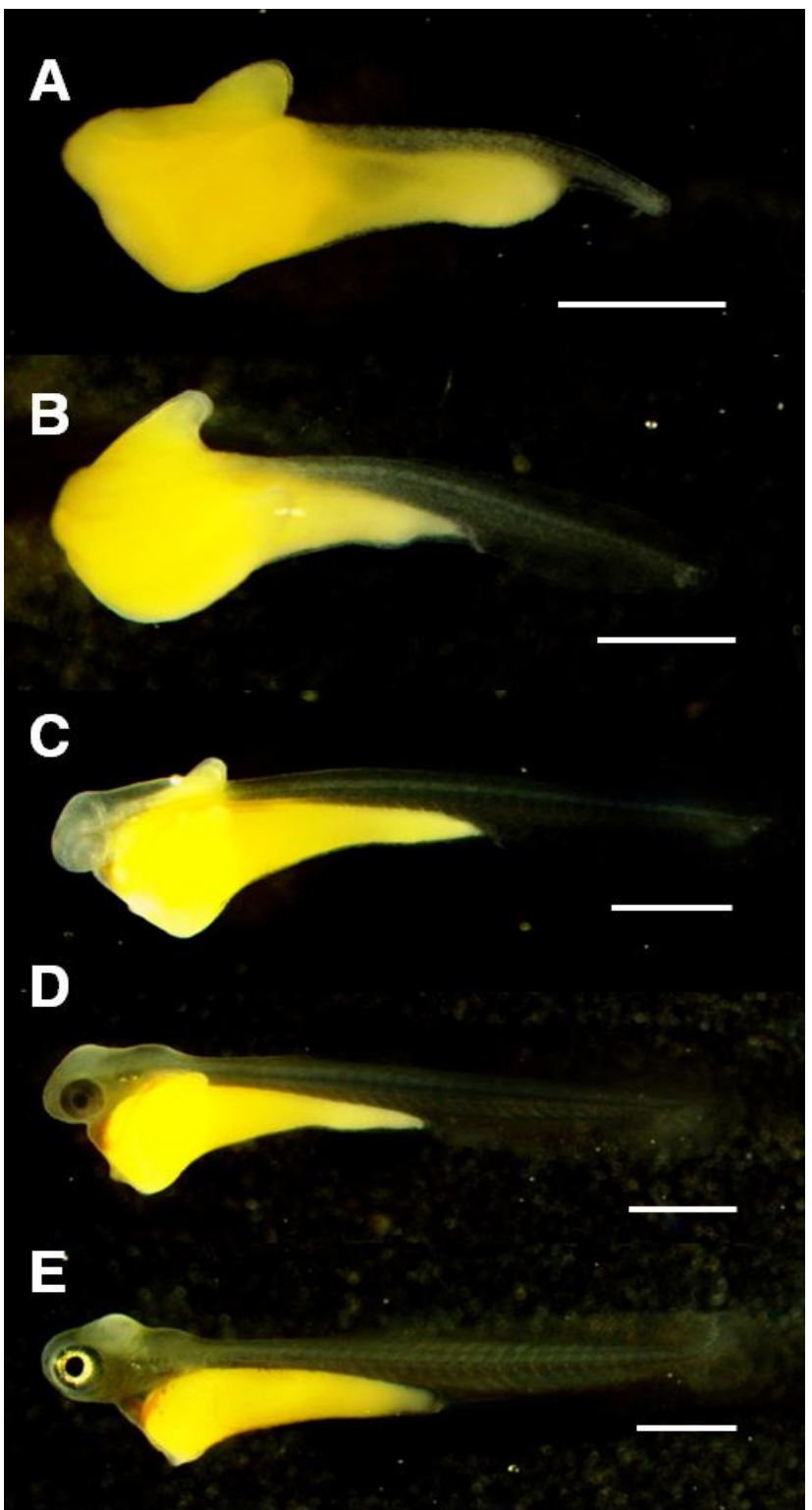

Fig. 6. Preflexion and flextion larvae development of Rhodeus ocellatus. A: Newly hatched larvae, 3.67 $\mathrm{mm}$ in total length (TL); B: 1 days after hatching, $4.82 \mathrm{~mm}$ in TL; C: 3 days after hatching, $6.06 \mathrm{~mm}$ in TL; D: 5 days after hatching, $6.57 \mathrm{~mm}$ in TL; E: 8 days after hatching, $7.10 \mathrm{~mm}$ in TL. Scale bars= $1.0 \mathrm{~mm}$.
$6.10 \mathrm{~mm}$ (average $6.06 \pm 0.05 \mathrm{~mm}$ ). The head developed and the eyes formed and a pair of protrusions formed on both sides (Fig. 6C).

On the 5 days after hatching, the pre-larvae were 6.54$6.61 \mathrm{~mm}$ (average $6.57 \pm 0.04 \mathrm{~mm}$ ), had black vesicles deposited on the eyes and the tip of the caudal fin began to differentiate and develop into a fan shape (Fig. 6D).

On the 8 days after hatching, the mid-larvae were 7.08$7.13 \mathrm{~mm}$ (average $7.10 \pm 0.03 \mathrm{~mm}$ ), developed lenses in the eyes, the brains developed, and the pair of protrusions that formed on both sides of the yolk disappeared. The vertebra of the tail began to bend to 45 , and 10 stalks were formed in the caudal fin (Fig. 6E).

On the 11 days after hatching, the mid stage larvae were 7.40-7.45 $\mathrm{mm}$ (average 7.42 $\pm 0.03 \mathrm{~mm}$ ), had twig shaped black vesicles deposited at the upper parts of the head, and yolk. Black vesicles were deposited in the form of line or dotted line. As the anal fin differentiated 8 stems were formed and 18 caudal fin stems were formed (Fig. 7A).

On the 17 days after hatching, the post stage larvae were $8.11-8.13 \mathrm{~mm}$ (average $8.12 \pm 0.01 \mathrm{~mm}$ ), swam above water as the air bladder developed and started to eat food after absorbing all the yolk. Twig-shaped black vesicles were deposited on the lower abdomen, back and anal fins, and spot-like black vesicles were deposited along the stems on the caudal fin. Number of fin stems for each part increased to 12 in the dorsal fin, 11 in the anal fin, and 19-20 in the caudal fin (Fig. 7B).

On the 25 days after hatching, the post stage larvae were $8.20-8.23 \mathrm{~mm}$ (average $8.21 \pm 0.02 \mathrm{~mm}$ ) had dark vesicles deposited on the head and the upper part of the air bladder was darkly colored and the whole body was dark black. Four gill glands were observed in the gill lid, and there were opening and closing movements. The dorsal fins at this period increased to 13 , and the caudal fins split into two halves with rounded ends (Fig. 7C).

On the 36 days after hatching, the post stage larvae with the total length of $9.20-9.23 \mathrm{~mm}$ (average $9.21 \pm 0.02 \mathrm{~mm}$ ) 


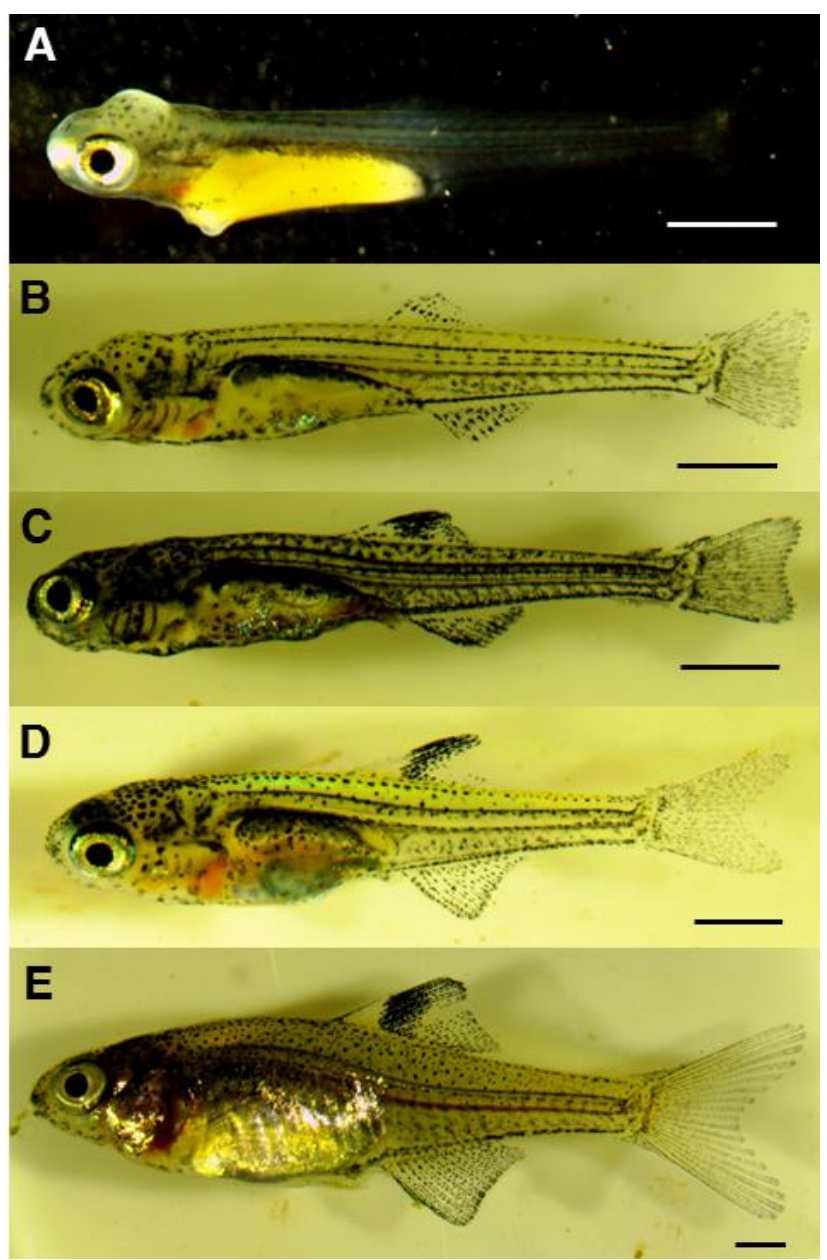

Fig. 7. Postflexion larvae and juvenile development of Rhodeus ocellatus. A: 11 days after hatching, 7.42 $\mathrm{mm}$ in total length (TL); B: 17 days after hatching, $8.12 \mathrm{~mm}$ in TL; C: 25 days after hatching, $8.21 \mathrm{~mm}$ in TL; D: 36 days after hatching, $9.21 \mathrm{~mm}$ in TL; E: 58 days after hatching, $15.9 \mathrm{~mm}$ in TL. Scale bars $=1.0 \mathrm{~mm}$.

disappeared in black vesicles that had been deposited in the lower abdomen and dark spotted vesicles were darkly colored at the top of the head. The number of dorsal fin stems were increased to 13 (Fig. 7D).

At 58 days after hatching, the juvenile fish were 15.8$16.0 \mathrm{~mm}$ (average $15.9 \pm 0.14 \mathrm{~mm}$ ), started to show a silver white color in the upper part of the gill and the abdomen and the dorsal fin had darkly colored black spots. The number of fin stems per each part increased to III-11 dorsal fins, III-12 anal fins, and iii-5 ventral fins (Fig. 7E).

\section{DISCUSSION}

The egg of the R. uyekii was shaped like a pear and the color of the yolk was milky white. This result was consistent with the report of Kim \& Han (1990). The color of the $R$. ocellatus yolk was lemon yellow with the egg in the form of an ovoid when coming out through the ovipositor but became pear shaped after absorbing water. Kim \& Park (1985) classified them as pear shaped, Kim et al. (2011) classified them as light bulb shaped showing differences in classification. Acheilognathus koeensis (Kim et al., 2011) was spindle shaped with the yolk color being light yellow, and A. majusculus (Kim et al., 2014) was ovoid shaped with the yolk color being light yellow as well. A. lanceolatus (Suzuki \& Jeon, 1990a) was spindle shaped with the yolk color being milky white and A. yamatsutae (Suzuki \& Jeon, 1987) was ovoid shaped with the yolk color being yellow. A. signifer (Baek \& Song, 2005) was pear shaped with the yolk color being a deep yellow, and A. macropterus (Kim et al., 2012b) was long ovoid shaped with the yolk color being light yellow. R. pseudosericeus (Kim et al., 2006) reported the shape to be a spindle-like pear but it was closer to a light bulb shape and the color of the yolk was light yellow showing differences in various egg shapes and yolk colors for each type.

The average size of the fertilized egg (embryo) of the $R$. uyekii was $3.68 \times 1.45 \mathrm{~mm}$ where the longest diameter was larger and the shortest diameter smaller than that of the average size of the fertilized egg (embryo) of $R$. uyekii in Nakdong River Sangdong-myeon, located in Sangdongmyeon, Gimhae-si, Gyeongbuk, reported by Kim and Han (1990).

The average size of the fertilized egg (embryo) of $R$. ocellatus was $2.62 \times 1.53 \mathrm{~mm}$ and the habitat of the $R$. uyekii reported by Kim \& Park (1985) was same as that reported by Kim \& Han (1990) and the average was $2.66 \times 1.51 \mathrm{~mm}$. The average length of the $R$. ocellatus (Suzuki \& Jeon, 1988a) of Anseong river was $2.68 \times 1.30 \mathrm{~mm}$ where the 
Table 3. Comparison of egg type and size in Acheiloganthinae fishes by each investigator

\begin{tabular}{|c|c|c|c|c|}
\hline Species & Habitat & Egg type & $\begin{array}{l}\text { Egg size }(\mathrm{mm}) \\
(\text { mean, } \\
\text { long } \times \text { short })\end{array}$ & Authors \\
\hline \multirow[t]{2}{*}{ Rhodeus uyekii } & Wi C. & & $3.68 \times 1.45$ & Present study \\
\hline & $\begin{array}{c}\text { Nakdong R. } \\
\text { (Gimhae, Sangdong) }\end{array}$ & Bulb like & $3.35 \times 1.65$ & Kim \& Han (1990) \\
\hline \multirow[t]{3}{*}{ R. ocellatus } & Wi C. & & $2.62 \times 1.53$ & Present study \\
\hline & $\begin{array}{c}\text { Nakdong R. } \\
\text { (Gimhae, Sangdong) }\end{array}$ & " & $2.66 \times 1.51$ & Kim \& Park (1985) \\
\hline & Anseoung $\mathrm{C}$. & & $2.68 \times 1.30$ & Suzuki \& Jeon (1988a) \\
\hline \multirow[t]{2}{*}{$\begin{array}{l}\text { R. notatus } \\
\text { (R. suigensis) }\end{array}$} & Anseoung C. & $"$ & $3.58 \times 1.17$ & Suzuki \& Jeon (1988b) \\
\hline & Balan C. & & $3.56 \times 1.39$ & \\
\hline$R$. pseudosericeus & $\begin{array}{c}\text { Namhan R. } \\
\text { (Hoengseong, Gonggeun) }\end{array}$ & $"$ & $2.80 \times 1.80$ & Kim et al. (2006) \\
\hline \multirow[t]{3}{*}{ Acheilognathus koeensis } & - & $\begin{array}{l}\text { Fusiform } \\
\text { (spindly) }\end{array}$ & $4.35 \times 1.76$ & Kim et al. (2011) \\
\hline & Sumjin R. & $"$ & $4.66 \times 1.49$ & \multirow{2}{*}{ Suzuki \& Jeon (1988d) } \\
\hline & Geum R. & $"$ & $3.19 \times 1.34$ & \\
\hline A. lanceolatus & Ungcheon C. & $"$ & $4.58 \times 1.49$ & Suzuki \& Jeon (1990a) \\
\hline \multirow[t]{3}{*}{ Acheilognathus signifer } & Naechon C. & Pear & $2.19 \times 1.85$ & Baek \& Song (2005) \\
\hline & Namhan R. & $"$ & $2.26 \times 1.74$ & \multirow{2}{*}{ Suzuki \& Jeon (1988c) } \\
\hline & Imjin R. & $"$ & $2.27 \times 1.82$ & \\
\hline A. somjinensis & $\begin{array}{c}\text { Sumjin R. } \\
\text { (Imsil, Sinpyeong and Gwanchon) }\end{array}$ & $"$ & $3.70 \times 2.30$ & Kim (1991) \\
\hline A. limbata & Sasagase R. in Japan & $"$ & $3.56 \times 1.79$ & Suzuki \& Jeon (1988d) \\
\hline A. rhombeus & Hantan R. & Ovoid & $2.58 \times 1.77$ & Suzuki \& Jeon (1991) \\
\hline A. yamatsutae & Bukhan R. & $"$ & $1.91 \times 1.57$ & Suzuki \& Jeon (1987) \\
\hline A. gracilis & Juksan C. & $"$ & $2.09 \times 1.26$ & Suzuki \& Jeon (1990b) \\
\hline A. majusculus & Yeong R. & $"$ & $2.12 \times 1.86$ & Kim et al. (2014) \\
\hline \multirow[t]{2}{*}{ A. macropterus } & Yeongam C. & $"$ & $1.95 \times 1.61$ & Suzuki \& Jeon (1989) \\
\hline & Ibaraki Prefecture in Japan & $"$ & $2.78 \times 1.44$ & Kim et al. (2012b) \\
\hline
\end{tabular}

C., cheon; R., river. 
longest diameter was found in Anseong river but the shortest diameter was the shortest of all.

Concerning the size difference of the fertilized egg (embryo) of the $R$. uyekii and the $R$. ocellatus, the longest diameter of the R. uyekii was rather larger. The R. ocellatus was small and the shortest diameter of the $R$. ocellatus was larger than the R. uyekii.

As for the size of the fertilized eggs (embryo) (long diameter $\times$ short diameter) compared to the same Aceilognathinae fish (Kim et al., 2011), the average of A. koeensis (Kim et al., 2011) was $4.35 \times 1.76 \mathrm{~mm}$, the average of Sumjin River fish (Suzuki \& Jeon, 1988d) was $4.66 \times 1.49 \mathrm{~mm}$, the average of A. lanceolatus (Suzuki \& Jeon, 1990a) was $4.58 \times 1.49 \mathrm{~mm}$ and the average of $A$. somjinensis (Kim, 1991) was $3.70 \times 2.30 \mathrm{~mm}$. These were larger in size than those of R. uyekii and R. ocellatus. Also, A. koeensis (Suzuki \& Jeon, 1988d) Geum River averaged 3.19×1.34 mm, and the R. notatus (Suzuki \& Jeon, 1988b) averaged 3.58× $1.17 \mathrm{~mm}$ in Anseong River and $3.56 \times 1.39 \mathrm{~mm}$ in Balan cheon. They were smaller than those of $R$. uyekii but larger than those of Sangdong-myeon, Gimhae and R. ocellatus (Table 3).

The hatching time was 48 hours for the $R$. uyekii in an average water temperature of $21.5^{\circ} \mathrm{C}$ which was similar to Kim \& Han (1990) which was 48 hours and 30 minutes when the water temperature was $16.5-18.5^{\circ} \mathrm{C}$. The hatching time was different but the water temperature was similar as Kim \& Park (1985) took 38 hours at an average water temperature of $21.2^{\circ} \mathrm{C}$. Suzuki \& Jeon (1988a) found it took 39 hours at an average water temperature of $22.0^{\circ} \mathrm{C}$, while the water temperature was $21.5^{\circ} \mathrm{C}$ for the $R$. ocellatus. Kim \& Park (1985) and Suzuki \& Jeon (1988a) show that the hatching start time is based on observation time. It is judged that there is a difference in results according to the observer as this study deemed a $50 \%$ hatching rate as its standard.

Compared with the same Aceilognathinae fish type, $A$. koeensis (Kim et al., 2011) took 49 hours when the average water temperature was $21.0^{\circ} \mathrm{C}, 45 / 47$ hours for Seomjin River and Geum River fish when the average water temperature was $22.0^{\circ} \mathrm{C}$ (Suzuki \& Jeon, 1990a), 62 hours for A. lanceolatus when the average water temperature was $22.0^{\circ} \mathrm{C}$ (Suzuki \& Jeon, 1990a), 39 hours for A. yamatsutae when the average water temperature was $22.0^{\circ} \mathrm{C}$ (Suzuki \& Jeon, 1987), 76 hours for Japanese A. macropterus when the average water temperature was $20.0^{\circ} \mathrm{C}$ (Kim et al., 2012b), 49 hours for $A$. signifer when the average water temperature was $20.0^{\circ} \mathrm{C}$ (Baek \& Song, 2005), 53 hours for fish in Namhan river and Imjin river when the average water temperature was $22.0^{\circ} \mathrm{C}$ (Suzuki \& Jeon, 1988c) and 70 hours $R$. pseudosericeus when the average water temperature was $17.0^{\circ} \mathrm{C}$ (Kim et al., 2006) and 43 hours for $R$. notatus when the average water temperature was $22.0^{\circ} \mathrm{C}$ (Suzuki \& Jeon, 1988b).

Aceilognathinae fish showed different hatching times per species even though they had similar water temperatures. The hatching water temperature was around $20.0^{\circ} \mathrm{C}$ similar to the water temperature in April-June, which is the natural spawning season. The optimal hatching water temperature according to the spawning season is closely related to the survival rate.

When comparing the size of the larvae right after hatching, the average total length of $R$. uyekii was $4.98 \mathrm{~mm}$ showing a difference as it was $4.30 \mathrm{~mm}$ for Kim \& Park (1985) and the average total length of $R$. ocellatus was $3.67 \mathrm{~mm}$ where for Kim \& Park (1985) it was $2.68 \mathrm{~mm}$.

In comparison with other Aceilognathinae fish, the total length of $A$. majusculus (Kim et al., 2014) which was 4.23 $\mathrm{mm}$ was smaller than the average total length of $A$. koeensis (Suzuki \& Jeon, 1988d) which was $5.54 \mathrm{~mm}$ in Seomjin River. The average total length of the Geum river fish was $6.38 \mathrm{~mm}$, the average total length of the Japanese Sasagase river fish was $4.95 \mathrm{~mm}$, the total length of $A$. lanceolatus (Suzuki \& Jeon, 1990a) was 5.30-5.51 mm, the average total length of Japanese A. macropterus (Kim et al., 2012b) was $5.60 \mathrm{~mm}$. The average total length of $A$. somjinensis 
(Kim, 1991) was $5.20 \mathrm{~mm}, R$. notatus from Anseong river was $4.31 \mathrm{~mm}$ and $4.03 \mathrm{~mm}$ in Balan river but larger than R. uyekii and R. ocellatus. A. yamatsutae (Suzuki \& Jeon, 1987) was 3.79-3.82 mm, Nam river A. signifer (Suzuki \& Jeon, 1988c) $3.65 \mathrm{~mm}$, A. signifer (Baek \& Song, 2005) 3.32-3.41 mm, A. gracilis (Suzuki \& Jeon, 1990b) 3.31 $\mathrm{mm}, R$. pseudosericeus (Kim et al., 2006) $3.30 \mathrm{~mm}$, Imjin river A. signifer (Suzuki \& Jeon, 1988c) $3.25 \mathrm{~mm}$, and $A$. macropterus (Suzuki \& Jeon, 1989) was $3.04 \mathrm{~mm}$ which was smaller than $R$. uyekii, but larger than $R$. ocellatus.

Aceilognathinae fish hatching larvae are classified into Rhodeus (pterygoid process developed in yolk) and Tanakia (development of fine epidermal process in round yolk) depending on the presence or absence of the pterygoid process. These protrusions are believed to be related to life-cycle habits that depend on not being thrown out of the shell during the preflexion stage (Kim et al., 2011). R. uyekii hatching larvae had a pair of pterygoid processes on both sides of the head, and one protrusion was formed in the lower part. The extinction period of the protrusions was before the completion of the absorption of the yolk which was on the eleventh day after hatching. $R$. ocellatus had a pair of pterygoid processes in the back of the head and one protrusion was formed in the lower part, and all the protrusions disappeared before the yolk absorption was completed on the 13 days after hatching.

A. koeensis (Kim et al., 2011) did not have a pterygoid process, but had fine epidermal protrusions, and the protrusions disappeared at the time when the yolk was full on the eighth day after hatching. A. majusculus (Kim et al, 2014) did not have a pterygoid process, and there are fine protrusions on the yolk surface. A. lanceolatus (Suzuki \& Jeon, 1990a) and A. yamatsutae (Suzuki \& Jeon, 1987) had clinoid processes on the back which disappeared on the 7 days after hatching. A. signifer (Suzuki \& Jeon, 1988c; Baek \& Song, 2005) is known to form epidermal protrusions on the whole surface of the body which completely disappears 20 days after hatching. The form of the protru- sions and the locations differed by each species.

As a result of comparing the time it took to get to the postflexion stage, it has been found that the $R$. uyekii took 23 days after hatching with a length of 8.97 , Kim \& Han (1990) took 22 days with a length of $9.10 \mathrm{~mm}$ while $R$. ocellatus took 17 days after hatching with a length of 8.12 mm and Kim \& Park (1985) took 30 days after hatching with a length of $8.50 \mathrm{~mm}$. $R$. uyekii took similar time to move on while there was difference in the total length. The $R$. ocellatus showed difference in the total length as the observation period of Kim \& Park (1985) was later than the result of this study. A. majusculus (Kim et al., 2014) took 20 days after hatching with a length of $10.12 \mathrm{~mm}$ to move on, A. lanceolatus (Suzuki \& Jeon, 1990a) took 11 days after hatching with a length of $9.70 \mathrm{~mm}$, A. yamatsutae (Suzuki \& Jeon, 1987) took 18 days after hatching with a length of $7.39 \mathrm{~mm}, R$. pseudosericeus (Kim et al., 2006) took 15 days after hatching with a length of 8.20 $\mathrm{mm}$, A. signifer (Baek \& Song, 2005) took 12 days after hatching with a length of $8.81 \mathrm{~mm}$, and Japanese $A$. macropterus (Kim et al., 2012b) took 15 days after hatching with a length of $8.20 \mathrm{~mm}$ which shows that the total lengths differed per species. The $R$. uyekii took the most days for moving on and A. lanceolatus was the fastest among similar species.

The time spent moving on to the juvenile stage $R$. uyekii took 56 days to move on with a length of $15.6 \mathrm{~mm}$, Kim \& Han (1990) 50 days after hatching with a length of 14.5 $\mathrm{mm}, R$. ocellatus 58 days after hatching with a length of $15.9 \mathrm{~mm}$ and Kim \& Park (1985) took approximately 2 months after hatching with a length of $14.4 \mathrm{~mm}$ which shows that $R$. uyekii had some differences in time and total length while the $R$. ocellatus took similar time even though the total length was somewhat longer. A. koeensis took 70 days after hatching with a length of $20.4 \mathrm{~mm}$, A. majusculus took 50 days after hatching with a length of $15.03 \mathrm{~mm}$ and $R$. pseudosericeus took 40 days after hatching with a length of $13.6 \mathrm{~mm}$ showing various differences of total 
lengths per species. The $R$. pseudosericeus took the least time to move on.

Therefore, according to these study results, there was a difference in the longest and shortest diameter Therefore, the results of this study are as follows. Compared with the previous studies, there were differences in the size of the longest and shortest diameters of the R. uyekii and R. ocellatus by water system. The morphology of hatching larvae did not show much difference, but $R$. ocellatus showed difference in size. Recently, A. koeensis, which was classified as the same species, reaffirmed the genetic and developmental differences and identified a new species called $T$. latimarginata (Kim et al., 2014). In order to elucidate these characteristics in the future, it is necessary to confirm the differences in embryology through the study of early life history by water system.

\section{REFERENCES}

Arai R (1988) Fish systematics and cladistics. In: Ueno T and Okiyama M (ed), Ichthyology Currents 1988. Tokyo Asakurashoten, Tokyo, pp 4-33.

Balon EK (1985) The theory of saltatory ontogeny and life history models revisited. In: Balon EK (ed), Early Life Histories of Fishes: New Developmental, Ecological and Evolutionary Perspectives. Dr W Junk Publisher, Dordrecht, pp 13-28.

Baek HM, Song HB (2005) Egg morphology and early life history of Acheilognathus signifer (Cyprinidae). Korean J Ecol 28:281-286.

Bănărescu P (1990). Zoogeography of fresh waters. Vol. 1, General distribution and dispersal of freshwater animals. In: Zoogeography of Fresh Waters, vol. 1: General Distribution and Dispersal of Freshwater Animals. AULA-Velag, Wiesbaden, pp 71-94.

Blexter JHS (1974) The Early Life History of Fish. SpringVerlag, Berlin, p 765.

Kim BS, Kang EJ, Jang H, Park IS (2012a) Morphometic traits and cytogenetic analysis in induced cross and reciprocal hybrid between Rhodeus uyekii and $R$. notatus. Korean J Ichthyol 24:151-159.

Kim CH (1991) Systematic studies on the bitterlings, genus Acheilognathus (Pisces: Cyprinidae) from Korea. Ph. D. Dissertation, Chonbuk National University, Jeonju, pp 73-77.

Kim CH, Choi WS, Kim DH, Beak JM (2014) Egg development and early life history of Korean endemic species, Acheilognathus majusculus (Acheilognathinae). Korean J Ichthyol 26:17-24.

Kim CH, Kang EJ, Kim JH (2006) Development of eggs and early life history of Korean bitterling, Rhodeus pseudosericeus (Acheilognathinae). Korean J Ichthyol 18:266-272.

Kim CH, Ishinabe T, Kim MK, Kim WJ (2012b) Development of eggs and early life history of Acheilognathus macropterus (Acheilognathinae) from Japan. Korean J Ichthyol 24:101-109.

Kim CH, Lee WO, Lee JH, Beak JM (2011) Reproduction study of Korean endemic species Acheilognathus koreensis. Korean J Ichthyol 23:10-20.

Kim D, Jeon HB, Suk HY (2014) Tanakia latimarginata, a new species of bitterling from the Nakdong River, South Korea (Teleostei: Cyprinidae). Ichthyol Explor Freshwaters 25:59-68.

Kim YU, Han KH (1990) Early life history of the Korean bitterling, Rhodeus uyekii (Cyprinidae) reared in the laboratory. Korean J Ichthyol 2:159-168.

Kim IS, Choi Y, Lee CL, Lee YJ, Kim BJ, Kim JH (2005) Illustrated Book of Korean Fishes. Kyo-Hak Publishing, Seoul, Korean. pp 106-112.

Kim YU, Park YS (1985) Egg development and larvae of the rose bitterling Rhodeus ocellatus (KNER). Korean J Fish Aquat Sci 18:586-593.

Okiyama M (1988) An Atlas of the early Stage Fishes in Japan. Tokai University Press, Tokyo.

Song HB, Choi SS (2000) Reproductive ecology and early 
life history of paradise fish, Macropodus chinensis (Pisces; Belontidae) in aquarium. Korean J Limnol 33: 282-294.

Suzuki N, Jeon SR (1987) Development of the bitterling, Acheilognathus yamatsutae (Cyprinidae), with notes on minute tubercles on the skin surface and paryngeal apparatus. Korean J Limnol 20:229-241.

Suzuki N, Jeon SR (1988a) Development of eggs, larvae and juveniles of Rhodeus ocellatus from Ansong-river, Korea (Pisecs: Cyprinidae), with a note on minute tubercles on the skin surface. Korean J Limnol 21:1-15.

Suzuki N, Jeon SR (1988b) Development of egg and larvae of the bitterling, Rhodeus suigensis (Cyprinidae) from Korea, with a note on minute tubercles on the skin surface. Korean J Limnol 21:231-242.

Suzuki N, Jeon SR (1988c) Development of the bitterling, Acheilognathus signifer (Cyprinidae), with a note on minute tubercles on the skin surface. Korean J Limnol
21:165-179.

Suzuki N, Jeon SR (1988d) Development of the bitterling, Acheilognathus limbata (Cyprinidae) from Korea and Japan, with notes on minute tubercles on the skin surface and on the genetic implication in hybrid embryos. Korean J Limnol 21:211-229.

Suzuki N, Jeon SR (1989) Development of the bitterling, Acanthorhodus asmussi (Cyprinidae) with note on minute tubercles on the skin surface. Korean J Ichthyol 1:73-82.

Suzuki N, Jeon SR (1990a) Development Acheilognathus lanceolatus from Ungchon river, Korea. Korean J Ichthyol 2:77-87.

Suzuki N, Jeon SR (1990b) Development of bitterling, Acanthorhodeus (=Acheilognathus) gracilis (Cyprinidae), with a note on minute tubercles on the skin surface. Korean J Ichthyol 2:169-181. 